\title{
Analysis of the Effects of the Implementation of the Sustainable Urban Development Strategy
}

\author{
Keranka Nedeva* \\ Department Management and marketing Agricultural university - Plovdiv, Bulgaria
}

\begin{abstract}
The study traces the results of the implementation of the Strategy for Sustainable Urban Development, as well as the integrated plans for urban regeneration and development and possible positive results that coincide with the requirements for the organization and construction of a Smart city. A sustainable city must allow long-term development without compromise for future generations. The aim of the study is to draw attention to taking adequate measures in the development of such urban development plans that contain elements of Smart city. Methods for document analysis, comparative analysis of plans and requirements for building a smart city were used. The concept of a sustainable city requires balancing goals for social, economic, environmental and managerial factors.
\end{abstract}

\section{Introduction}

The research of the impact of the urban environment and the overcrowding of cities in the new world is a priority of the World Health Organization (WHO), which considers the restoration of urban contact with nature as a necessary condition for improving the health of the population [1]. Half of the world's population currently lives in cities, and by 2050 this will be nearly $66 \%$ [2].

That, on one hand, leads to increased exposure to number of health risk factors, and on the other, limits the contact with nature.[3]

The increase in the number, role and size of cities leads not only to an increase in the relative share of the urban population, but also to a change in the functions of cities and the distribution of the urban way of life. In connection with this, the model of the "smart city" is emerging, which meets the challenges of evolving technological and environmental changes. The design, construction and operation of smart cities provides the opportunity to create effective solutions for optimal use and saving of energy, reduce the consumption of nonrenewable resources, control of environmental waste, ensure sustainable development, optimize the efficiency of urban systems, which leads increased the quality of life of the population.

Creating modern policies to solve social, a technological and environmental problems is the main challenge for building and managing smart cities. They have deal simultaneously with economic development, urbanization and the creation of public services, poverty reduction, environmental protection, the socialization of cultural and historical heritage. To activate this "mechanism" it is necessary to unite societies (citizens), institutions, academia, non-governmental sector and business around the great opportunities of new technologies to build a long-term vision for sustainable development of modern cities.

Cities must be considered as a whole living organism. Like other organisms, cities are located in nature. Nature provides challenges and opportunities. A city survives and thrives depending on how it responds to the challenges and opportunities that are presented to it. The essence of "Smart City" is the ability to adapt to changes in nature. Its capacity to evolve and its capacity to evolve and to transform if is necessary. The city's capabilities are limited by the resources available.

The most basic resource of a city is the human factor the abundance of intellectual capacity of the population, self-confidence, entrepreneurial spirit.

We are all part of one system and each of us with his ideas can influence this system. If we want change, change must start with ourselves.

\section{Definition of smart city}

The idea of digitizing cities is to make traditional services faster and easier, thus saving citizens time. The "Smart city" must have LED lighting, turn its waste into energy, contain sensors to study air quality. Other things that Smart City can contain are micro-networks for electricity generation, high-speed rail transport and others. In short, "smart city" must be sustainable development. Definitions of "smart city" include socio-economic and managerial aspects, such as the use of social participation to improve sustainability, quality of life and urban welfare.

* Corresponding author: knedeva.au@abv.bg 
The smart city uses information, information and The smart city can process information from various sources to improve its results in all its activities [4].

communication technologies and the Internet to solve the city's problems [5].

Smarter cities of different sizes are capitalizing on new technologies and their vision to transform their systems, activities and services. A city can be called "smart" when investments in people and social capital, in information and communication infrastructures, contribute to sustainable development and a high quality of life, through good governance, of natural resources and which is open and committed to citizens [6].

A smart city is a place where traditional networks and services are made more efficient with the help of information and communication technologies for the benefit of citizens and businesses.

A smart city is a city that functions well in terms of six "smart" characteristics (economy, mobility, environment, governance, living and people), and is built on a "smart" combination of donation/sharing and activities of independent and knowledgeable about the problems of the city citizens. [7]

The "smart city" is an innovative concept that uses technology to improve competitiveness and ensure a more sustainable future through a symbiotic connection of networks of people, businesses, technology, infrastructure, consumption, energy and space.

The smart city is a city that responds to societal problems through solutions based on new information technologies. These solutions are developed and synthesized through Smart City initiatives or as separate projects or as a network of overlapping activities.

In particular, Smart City strategies must include at least one of the following characteristics: smart governance, educated people, cultural life, smart mobility, an innovative economy and a smart environment.

The new indicator for innovative development of the EC reports significant differences between EU22 member states [8]. One of the reasons for these differences is the insufficient critical mass of research centers and centers that have the necessary competencies and capacity to engage countries and regions in the process of innovative growth and development of innovation capacity [9]. Bulgaria lags significantly behind in terms of research and innovation, although it has made little progress compared to 2014, when it was last in the rankings.

The latest monitoring report for the EU Member States24 [10] states that:

- Bulgarian industry is still characterized by low productivity and low level of innovation;

- Although Bulgarian companies have low taxes and fees (for example - $10 \%$ corporate tax), they do not invest enough in research and innovation;

It is clearly that in order improve its competitiveness, the country must focus its efforts on creating an innovative ecosystem that will stimulate cooperation in the "triangle of knowledge" (academia, business and government institutions).

\section{Bulgarian smart sities}

\subsection{Dynamics and development of the population of Bulgaria since the beginning of the XXI century}

For a quarter of a century, Bulgaria has been showing significant demographic losses which is a result of negative natural and mechanical growth. The population of Bulgaria between the two censuses in 1992-2001 decreased by 558 thousand people, and by 2011 by another 564 thousand people, in 2016 - 243 thousand people, in 2019 - 150 thousand people.

The decrease in the negative rate is a result of increasing the birth rate and limiting the emigration processes. In other words, for a period of nearly thirty years the population of Bulgaria has decreased by $16 \%$, and only since the beginning of the new millennium by $10 \%$.

The rates of population decline in towns and villages vary considerably. As a result, the number of urban populations decreased for the period $1992-2016$ by $8.6 \%$ (only for the period 2001-2016 by 4.7\%), and of the rural population by $31.3 \%$ (only for the period $2001-2016$ with $22.1 \%$ ). As a result of the different intensity of the change in the population, the relative share of the urban population increased from $67.2 \%$ in 1992 to $73.2 \%$ in 2016 [11].

The serious territorial disparities it is another important demographic problem in Bulgaria. The trend of depopulation of many villages, which are located mainly in mountainous and peripheral areas, continues.

\subsection{The strategic initiatives for intelligent specialization of Sofia}

In Bulgaria, Sofia is the only city that has an innovative strategy for smart development. The aim is to increase the level of intelligent specialization of the capital by establishing Sofia as a city that builds an environment with high quality of life for citizens and good governance, stimulating the creation of better conditions for synergy and partnership in the innovation ecosystem and through efficient use. of Information and Communication Technologies (ICT).

Sofia's smart specialization has a positive impact on sectors that have a direct bearing on the quality of life in the city, such as: environment (ecology, resource efficiency), energy efficiency, production, transport infrastructure and mobility, healthcare, education, media, social services and social capital.

Sofia's economy has been developing at a very high pace in the last decade. The GDP produced in the capital creates about four times and reaches $39 \%$ of the GDP in Bulgaria in 2010. For comparison, in 2000 the GDP of the capital is $27 \%$ of the next country. Sofia already produces average GDP per capita of $38 \%$ for EU members (after Bratislava - 69\% and Bucharest - 55\%).

Sofia envisages the implementation of numerous strategic initiatives and projects that will create 
conditions for a complete change of the innovation ecosystem in Sofia and will catalyze such a change within the South-West region and the whole country. Sofia is effectively involved in the European Innovation Partnership Smart Cities and Communities, as well as in many other European initiatives and partnerships related to smart city development, for example - in the network of Open and Flexible Smart Cities, which offer innovative solutions not only in the field of digital technologies and cultural and creative industries, but also in energy efficiency, transport, healthcare, etc. Special attention in the implementation of the strategy will be paid to the development of services for citizens, businesses and administration based on open data, as well as the digitization of cultural and historical heritage and language resources, which is a prerequisite for successful synergy between the two thematic areas selected. of priority focus of Sofia.

"Vision for Sofia“ is an initiative of Sofia Municipality to create a shared and long-term strategy for the development of the capital and suburban areas until 2050. The project has the ambition to analyze the current state of Sofia and propose specific steps, measures and goals for future sustainable development of the city. Achieving this task is possible only with the combined efforts of citizens, business, science, NGOs and administration.[12]

Similar visions and long-term strategic documents for the comprehensive development of cities and regions have been created in many parts of the world. The work on creating a Vision for Sofia includes a study of international experience. Examples from Barcelona, Berlin, Boston, Vienna, Tel Aviv, Goteborg, Copenhagen, London, Brno, Rotterdam, Stockholm, Sao Paulo, Helsinki are discussed in more detail. There was also direct contact with the teams that worked on similar processes in Boston, Vienna, Tel Aviv, Barcelona, Copenhagen.

The preparation of the Vision requires the creation of a platform for an informed conversation about the future of the city, in which all people and organizations determining the development of Sofia can participate: municipal authorities, non-governmental organizations, investors, researchers, experts and citizens. The aim is to seek consensus and more effective interaction between the shared ambitions and goals for the development of Sofia, so as to improve the process of urban planning. Special attention in the planning of the process is paid to the communications, which aim to significantly expand the scope of interest in the initiative and to include as many people and organizations as possible in a dialogue about the possible directions for development of the capital. In order to ensure more efficient and transparent work, a Monitoring team is formed like mirror image of the Vision team, whose task is to monitor, criticize and direct the work of the main coordination team and to prepare reports with its observations and recommendations at the end of each important stage of the process.
The process of creating a Vision for Sofia is synchronized with other current initiatives related to the future development of Sofia Municipality, such as „City for the People“, „Plan for Sustainable Urban Mobility“, „Green Sofia“, „Pre-investment study of water supply and sewerage infrastructure" and other.

Following the steps of the pre-drawn clear and transparent methodology, Vision for Sofia and the municipal enterprise „Sofproect" carry out a total of over 50 surveys, collect and analyze databases and seek answers to problematic topics in the city on key issues of living conditions in him. A significant part of the data has been digitized and turned into maps, graphs and a comprehensive library of reports and developments, which should be maintained and upgraded in order to monitor the progress of the implementation of the Vision in the future. The Vision team has formulated 24 longterm goals, nearly 250 steps and 385 specific measures, which have the ambition to draw up a plan for making Sofia a better city to live. The long-term vision is for 2050 Sofia to be a compact, diverse and adaptable city, skillfully managing its resources and involving citizens in decisions for the future.

Sofia is the fastest growing city in Bulgaria, and the private car remains the preferred mode of transportation, leading to heavily congested intersections and the accumulation of cars parked on the streets. In addition, there is a lack of infrastructure to meet the growing needs of the city. It is these problems that the GEMSS project addresses. Its activities are directly aimed at $28.8 \%$ of citizens (about 350 thousand people) who use cars on daily basis according to the Plan for Sustainable Urban Mobility of 2019. The introduction of data-based solutions will reduce travel time to the workplace, reduce driving stress, reduce road infrastructure congestion and greenhouse gas emissions from road traffic, and thus improve the urban landscape and quality of life in Sofia.

Open Innovation Competition - GEMSS - is a competition for innovation and generating ideas for solving the problems of excessive traffic and parking on the streets in one of the districts in Sofia - Lyulin district. The aim is that the created solutions can then be applied in other areas.

Green Sofia is a partner in the GEMSS project (GEoModeling for Integrated Mobility Solutions in Sofia) under the EIT Urban Mobility program, together with Cleantech Bulgaria, Sofia University "St. Kliment Ohridski" and Center for Urban Mobility. The aim is to improve public transport activities, including the development of intermodal hubs, buffer car parks and transport to key points (Park and Ride stations), as well as to promote road transport alternatives that reduce the load on the streets from parked cars, reduce the use of private cars, while increasing the living space used.

In August 2019 in Sofia began offering the first service for shared use of electric scooters. More and more people in the city are looking for alternatives to driving. Rent a new generation of mountain electric bikes from the center to Vitosha Nature Park is a pilot project was initiated by Green Sofia - Sofia Municipality and the 
Cleantech Bulgaria Sustainable Development Network, with the support of EIT Climate-KIC - the largest publicprivate partnership in the EU, supporting the development of green innovations, including a wide range from partners.

The aim of the project is to stimulate a change in the attitudes of Bulgarians towards the transition to ecological and healthy methods of transportation, reducing car traffic to Vitosha, as well as testing the needs and attitudes of consumers to the system itself. The reservation of electric bicycles is done through a specially designed application.

In the period from 4.09-15.09.2017, at the invitation of Sofia Municipality ("Green Sofia") and together with the Traffic Police Department of the Interior Ministry in the capital was carried out remote measurement of emissions from cars in real time and without the need for their stopping. The project was carried out by a team from the Spanish laboratory RSLab, who monitored the amounts of fine particulate matter (PM), hydrocarbons (HC), carbon monoxide (CO) and nitrous oxide (NOx). These are the main air pollutants.

The remote emission measurement process did not involve any interference with road traffic. It takes seconds and starts the moment the vehicle crosses the infrared (IR) and ultraviolet (UV) rays emitted by the system. The device can also record the speed and record the registration numbers in order identify emissions with the specific type of car, make, engine, year of manufacture. All measurement data is sent directly to a computer monitored by an operator located in a mobile station parked along the road.

The purpose of Guide to separate collection of household waste is to guide, facilitate and support the efforts of all concerned about the well-being of their street, their neighborhood, their city, their planet. The map shows the location of the different types of containers for separate waste collection, on municipal sites for secondary raw materials. The schedules for collection of construction and bulky waste by regions have also been uploaded.

Sofia is following the path of decarbonization of public transport. At the end of last year, the first 20 electric buses were delivered, and by the end of next year their number could triple. Moreover - the newest e-buses in Sofia (which have not yet been put into operation) are of the fast-charging type - they are powered by the socalled ultracapacitors, which are more compact and contain fewer potentially hazardous substances than batteries. This is an innovative technology that is just entering Europe, but this time Sofia is up to date. At the moment, the data of the municipality show that only 350 electric cars are registered in the city. however, their number in Europe will certainly grow rapidly in the coming years. most often the service is used by guests of the city and young people who do not have own car. A major change in perceptions will not occur until a few years from now.

\subsection{Good practices in other Bulgarian cities}

While the capital is making timid steps on the path to electric mobility, but other Bulgarian cities are overtaking it with larger projects and faster implementation. The most striking example is Burgas. Since 2010, the local government has been working on a complete transformation of its public transport. Today, all old buses have been replaced with new ones of the highest environmental class and equipped with constant video surveillance. Citizens can travel with electronic cards on all lines, which can be charged for a certain number of trips via a smartphone.

Three years ago, the municipality of Burgas launched small ecological buses, which use energy from the solar panels and are an alternative in the hot summer days. Another way to get around the city are electric bicycles.

Another Bulgarian city introduced a successful model for separate waste collection door to door a few years ago. In 2016, yellow containers for separate disposal of paper and plastic waste were placed in the yards of half of the houses and single-family buildings in Svilengrad. After proving that it can act effectively in an environmentally friendly direction, the city is invited to become part of the European Zero Waste Network - an organization that includes leading municipalities in the field of waste management, which have achieved municipal waste below $100 \mathrm{~kg}$ per person for year. Svilengrad is currently developing a project for the construction of an installation for compost production and plans to install containers for biodegradable waste in the future.

\section{The world and us}

The idea of a "named city" is not just a digital transformation, but a more sustainable development of the cities and an improvement in the quality of life of the people living.

The IMD-SUTD Smart City Index (SCI) assesses the perceptions of residents on issues related to structures and technology applications available to them in their city. The first edition of the SCI ranks 102 cities worldwide by capturing the perceptions of 120 residents in each city. There are two pillars for which perceptions from residents are solicited: The Structures pillar referring to the existing infrastructure of the cities, and the Technology pillar describing the technological provisions and services available to the inhabitants. Each pillar is evaluated over five key areas: health and safety, mobility, activities, opportunities, and governance. The cities are distributed into four groups based on the UN Human Development Index (HDI) score of the economy. Within each HDI group, cities are assigned a "Irating scale" (AAA to D) based on the perceptions-score of a given city compared to the scores of all other cities within the same group.

Being a globally - recognized 'smart' city is now critical for attracting investment and talent, creating a potential 'virtuous cycle' in favour of an advanced group of cities such as Singapore, Zurich and Oslo. 
"Smart cities are growing and blossoming in all parts of the world. Economic realities cannot be ignored: cities in poorer countries face disadvantages, which will require specific actions to correct along the path towards smartness," stated Professor Arturo Bris, Director of the IMD World Competitiveness Center. [13]

Sofia consolidates its 89th position in the global Smart City Index 2020.

In addition, Sofia preserves its "SS" rating (with the highest possible "AAA" and the lowest "D"). From a list of 15 indicators, survey respondents were asked to select 5 that they perceived as the most urgent for their city. The higher the percentage of responses per area, the greater the priority for the city: air pollution $-78.9 \%$, corruption $-77.2 \%$, road congestion $-67.5 \%$, security $-52.8 \%$ and green spaces and health services - 34\% [14].

It is important that digital technologies contribute to meaningful changes in people's lives and that they become truly real. In connection with this top 10 of the cities of 2019 as of Singapore (1), Zurich (2), Oslo (3), Geneva (4), Copenhagen (5), Auckland (6), Taipei City (8), Bilbao (9) and Dusseldorf (10)

On the front positions are cities with a small size. For big cities to become smart is more difficult. For example, Can Francisco, with a population of 884,000 it is ranked 12th, Bilbao, with a population of 350,000 is in 9th place, but Loc Angelic with a population of 4 million (35th place) and Barcelona is in 48th place (population of 5.5 million) [15].

There are 29 cities in the world with more than 10 million people, which is expected to increase by 2030 to 43. Differences between cities will continue to increase and digital solutions to urban problems will be seeking more and more. The real test will be whether the citizens benefit from the benefits.

\section{Conclusion}

Smart City improves the security of your city by connecting and automating intelligent technologies, starting with street lighting that adjusts to the level of illumination, waste containers with sensors, reducing jams, efficient operation of public transport, monitoring of utilities, accident prevention, apps that showing free parking spaces.

In short - things that make our daily lives much easier, and the living environment - cleaner and more pleasant. Of course, to be able to have all these facilities, we need technology - good enough to take a huge number of decisions, cheap enough to be accessible to more people and sustainable enough to meet the future innovations.

The case of "many people in small, concentrated spaces" will develop faster and faster. And as this process intensifies, there will be growing challenges for the municipalities that manage these areas, for the companies that provide them with services, and for citizens who seek even basic resources such as water or food. People believe that the solution is in the so-called "smart cities". They use technology to manage all the city's assets - transportation, hospitals, schools, plumbing, cleaning systems and more. The benefits of this are know. When information is collected, analyzed and managed properly, they make the management of a city more efficient, cheaper, and more enjoyable for those living in it. This research was supported by Bulgarian National Science Fund grand.

This research was supported by Bulgarian National Science Fund grand

\section{References}

1. Urban green spaces and health. Copenhagen: WHO Regional Office for Europe, (2016)

2. United Nations, Department of Economic and Social Affairs, Population Division. World Urbanization Prospects: The 2014 Revision, Highlights (ST/ESA/SER.A/352). (2014)

3. Djambov, A., V. Stoyanova, D. Dimitrova, Urban landscaping and public health - modern scientific achievement, Social medicine, 1, (2017)

4. http://ieeexplore.ieee.org/stamp/stamp.jsp?reload=tru e\&tp $=$ \&arnumber $=6682980$

5. http://www.cisco.com/web/about/ac79/docs/ps/motm /IoE-Smart-City_PoV.pdf

6. http://www.ibm.com/smarterplanet/us/en/smarter_cit ies

7. http://www.smart-cities.eu

8. http://ec.europa.eu/enterprise/policies/innovation/poli cy/innovation-scoreboard/

9. http://ec.europa.eu/research/participants/portal/deskt op/en/opportunities/h2020/topics/2535- widespread1-2014.html

10. http://ec.europa.eu/growth/industry/competitiveness/r eports/ms-competitiveness-report/index_en.htm

11. Bardarov, G., N. Ilieva, Demographic Trends in Bulgaria, Horizon 2030, Published by Friedrich Ebert Foundation, Sofia, (2018)

12. https://vizia.sofia.bg/

13. https://www.imd.org/researchknowledge/reports/imd-smart-city-index-2019/

14. https://www.economic.bg/bg/a/view/sofija-nakartata-na-umnite-gradove-vse-taka-na-dalechnoto-

15. IMD Smart City Index 2019 